\title{
MULTI-SCALE EXPERIMENTAL STUDY OF BLAST PROPAGATION AROUND A HEMI-CYLINDRICAL BARRIER
}

\author{
SOPHIE TRÉLAT ${ }^{1}$, MICHEL-OLIVIER STURTZER $^{2} \&$ DOMINIQUE ECKENFELS ${ }^{2}$ \\ ${ }^{1}$ IRSN, Institut de Radioprotection et de Sûreté Nucléaire, France \\ ${ }^{2}$ ISL, French-German Research Institute of Saint-Louis, France
}

\begin{abstract}
Interaction between large blast and targets can rarely only be directly studied, due to cost and practicality considerations. Blast tests using reduced-scale high explosive charges represent an attractive alternative. The first necessary step consists in studying blast propagation in free-field at the considered scales. The second step focuses on the determination of the blast load around various types of reference obstacles, in order to provide a critical input for numerical simulation. This approach also aims to build simplified models allowing faster risk assessment for government agencies. Since 2017, the French Institute for Nuclear Safety (IRSN) and the French-German Research Institute of SaintLouis (ISL) have been studying blast propagation in free-field and in front of a hemi-cylinder at two different reduced scales using Hexomax ${ }^{\circledR}$ charges. IRSN developed a significant experience on hemispherical blast effect assessment using $42 \mathrm{~g}$ reference Hexomax ${ }^{\circledR}$ charges detonated in contact with a planar surface supporting a hemi-cylindrical obstacle, both equipped with pressure sensors. Based on this experience, ISL developed its own outdoor blast-pad: $333 \mathrm{~g}$ Hexomax ${ }^{\mathbb{B}}$ charges are detonated in a factor two up-scaled version of IRSN test configuration. Similar sensors are flush-mounted on the pad and the surface of an up-scaled version of the IRSN obstacle. In addition, the fine structure of the shock transmitted into the air and propagating along the obstacle surface is studied using high-speed imaging. Two respective series of charges were detonated at distances between 0.6 and $3.5 \mathrm{~m} / \mathrm{kg}^{1 / 3}$ from the hemi-cylinder, in order to assess its influence on the wave reflection structure and the resulting blast load. High-speed images enabled the triple and contact points tracking on the obstacle. Finally, this project illustrates an innovative methodology not only to assess the blast load on a convex structure, but also the potential downstream protective effects of such a structure used as a barrier.
\end{abstract}

Keywords: blast wave, hemi-cylindrical structure, detonation, plastic explosives, reduced-scale charges, effect on infrastructures, experiments, convex, Mach reflection.

\section{INTRODUCTION}

The Institute for Radiological Protection and Nuclear Safety (IRSN) is a French public institute with industrial and commercial activities, placed under the joint authorities of the Ministries of Defence, Environment, Industry, Research, and Health. IRSN is entrusted, among others, to assess and conduct researches in the area of the protection of nuclear facilities and transport of radioactive and fissile materials against accidental and malicious acts. In this context, IRSN establishes projects and studies to improve its knowledge of blast characteristics and weapons effects.

The French-German Research Institute of Saint-Louis (ISL) is a bi-national research institute established by the Federal Republic of Germany and the French Republic on the basis of a treaty signed in 1958. The core mission of ISL is: "Research, scientific studies and basic predevelopment in the field of defence and security". Among other tasks, ISL focuses on the physical protection of personnel and assets against the effects of various explosive charges. To improve general survivability, fundamental studies on blast wave propagation and target interaction are continuously being conducted at ISL. 
In 2006, IRSN designed and built an experimental set-up to achieve non-destructive shock wave propagation studies on a small scale [1], [2]. This set-up is composed of a modular table, sensors and targets able to perform the detonation of solid explosives up to $64 \mathrm{~g}$ of TNT equivalent, representing an alternative to the gas mixture detonation propagation configuration for small-scale tests [3], [4]. Blast generated by $50 \mathrm{~g}$ TNT equivalent hemispherical Hexomax ${ }^{\circledR}$ charges was consequently characterized. To evaluate the effect of scale, a joint study between IRSN and ISL was initiated in 2017, based on a dedicated ISL blast pad replicating the IRSN table at a double scale: $400 \mathrm{~g}$ TNT equivalent hemispherical Hexomax $^{\circledR}$ charges are being investigated.

Based on literature and IRSN previous experimental results [5], [6], this document proposes innovative abacuses (Model S) to predict the three-dimensional peak overpressure on the expansion side of a convex non-deformable structure (simplified shape based on an actual transport cask or industrial facility and different from the more common box-like obstacle) depending on the reduced distance to the obstacle. Data collected during the 2018 joint IRSN-ISL campaign [6] on $400 \mathrm{~g}$ TNT equivalent charges are consequently compared to the model predictions. In addition, the fine structure of the shock wave bypassing the convex surface is studied using a high speed imaging setup based on direct lighting. The Mach stem height is measured in terms of triple point radius and angle of observation on cylinder. This height versus angle curve serves to establish the triple point time trajectory over the convex shape.

\section{EXPERIMENTAL SETUP}

\subsection{IRSN setup}

The IRSN blast table has been principally designed to study shock waves reflection phenomena and interaction with different non-deformable structures [2]. It measures $1.6 \times 2.4 \mathrm{~m}$ and features an array of mounting holes that facilitates the placement of modular $0.4 \times 0.4 \times 0.05 \mathrm{~m}$ wooden plates and pressure transducers (Fig. 1). Explosive charges are installed and ignited on a dedicated reinforced steel table plate to generate a hemispherical blast wave using a Davey-Bickford SA 4201A detonator. Experimental campaigns were performed at the ArianeGroup's research center located near Paris (Vert-le-Petit, France).

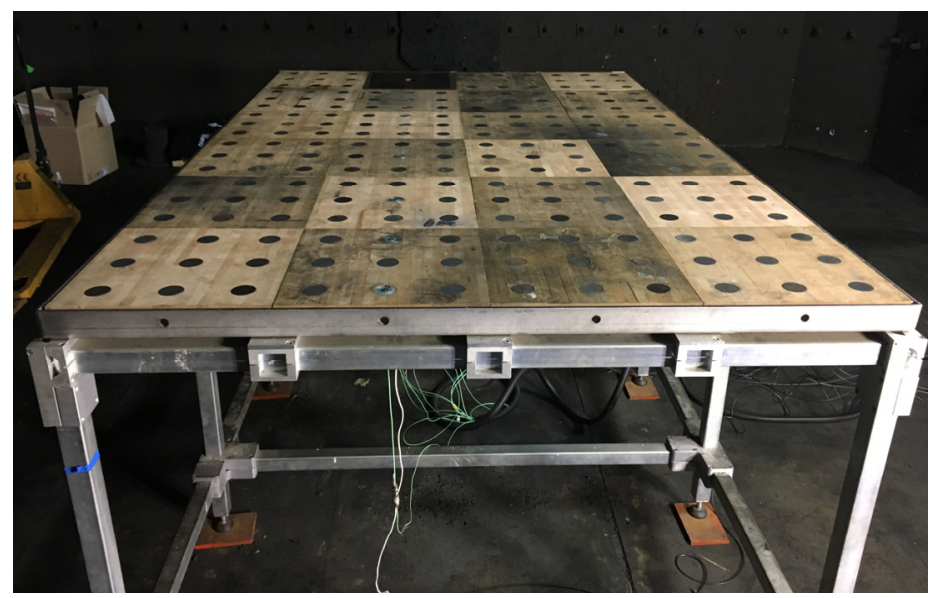

Figure 1: IRSN blast table. 
A wooden hemi-cylindrical structure was fixed on the table surface. The $0.4 \mathrm{~m}$ diameter hemi-cylinder has the same length $(1.6 \mathrm{~m})$ as the table in order to avoid lateral bypass of the shock wave (see Fig. 2). The target is sufficiently rigid to withstand repeated blast loading without damage nor deformation. Five pressure gauges separated by $30^{\circ}$ can be installed on the target surface along three vertical lines facing the explosive charge. For this campaign, five pressure transducers were mounted on elastic supports and their signals were recorded at $500 \mathrm{kHz}$ by a Nicolet Genesis data acquisition system.

Results presented in this document were acquired for three different d distances (Fig. 3): $0.4,0.8$ and $1.6 \mathrm{~m}$ (Table 1) [5]-[7].

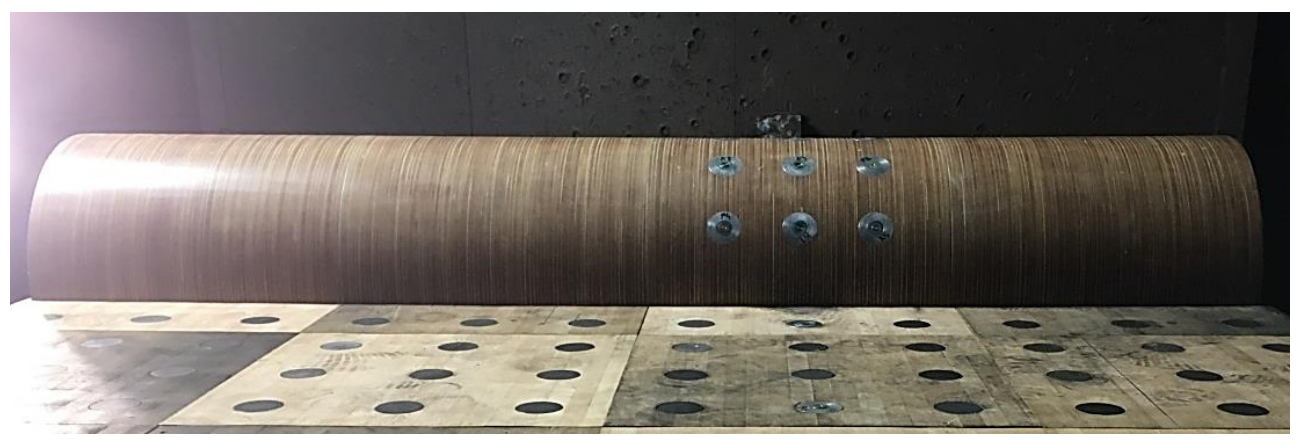

Figure 2: View of the wooden hemi-cylinder lying on the table with holes for sensor positioning.

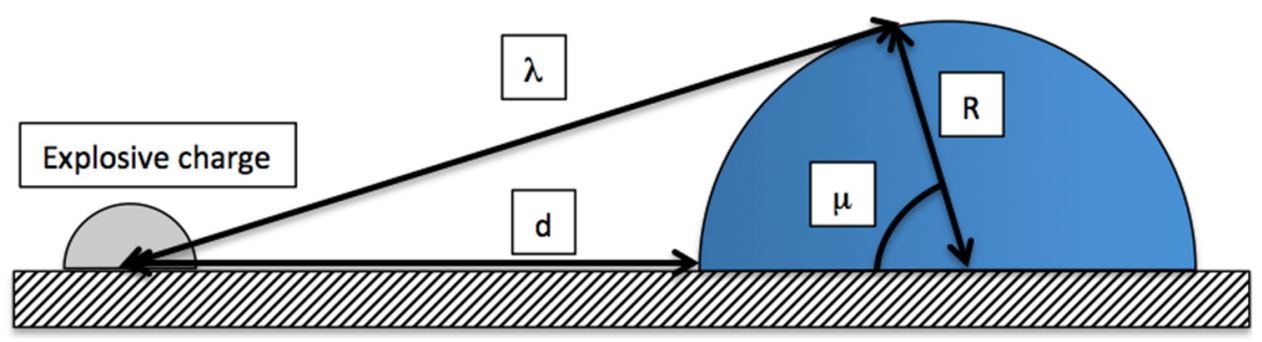

Figure 3: Diagram of the experimental configuration involving a hemi-cylinder.

Table 1: Hemi-cylinder metrology specifications.

\begin{tabular}{|c|c|c|c|}
\hline Angle $\mu$ & ISL PCB & ISL Kulite & IRSN Kistler \\
\hline $30^{\circ}$ & $\mathrm{x}$ & $\mathrm{x}$ & $\mathrm{x}$ \\
\hline $60^{\circ}$ & $\mathrm{x}$ & $\mathrm{x}$ & $\mathrm{x}$ \\
\hline $90^{\circ}$ & $\mathrm{x}$ & $\mathrm{x}$ & $\mathrm{x}$ \\
\hline $120^{\circ}$ & $\mathrm{x}$ & $\mathrm{x}$ & $\mathrm{x}$ \\
\hline $150^{\circ}$ & $\mathrm{x}$ & $\mathrm{X}$ & $x$ \\
\hline Lateral offset $(\mathrm{mm})$ & 0 & 50 & 0 \\
\hline $\mathrm{d}(\mathrm{m})$ & \multicolumn{2}{|c|}{3.2} & $0.4 / 0.6 / 1.6$ \\
\hline
\end{tabular}




\subsection{ISL setup}

ISL developed a dedicated outdoor blast pad (Fig. 4): explosive charges are detonated in a factor two up-scaled version of IRSN test configuration. Each explosive charge was installed on a dedicated reinforced steel ground plate to generate a hemispherical blast wave. Based on IRSN previous work, ISL also designed a factor two upscaled hemi-cylindrical obstacle (Fig. 5). The results obtained for two target configurations are described in this document:

- "long" hemi-cylinder composed of 4 segments ( $800 \mathrm{~mm}$ diameter and $3.2 \mathrm{~m}$ total length), - "short" single instrumented (5 lines of instrumentation ports) hemi-cylinder $(800 \mathrm{~mm}$ diameter and $0.8 \mathrm{~m}$ length).

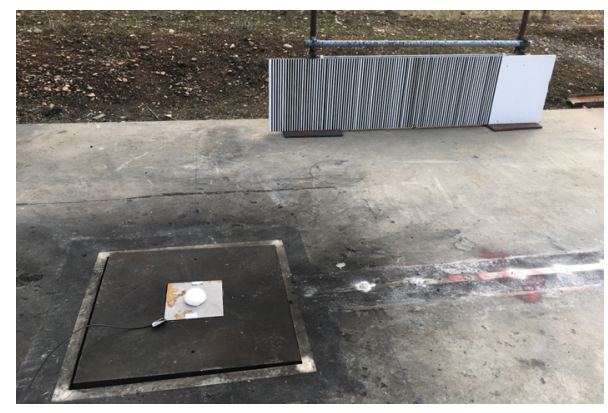

Figure 4: ISL blast pad.

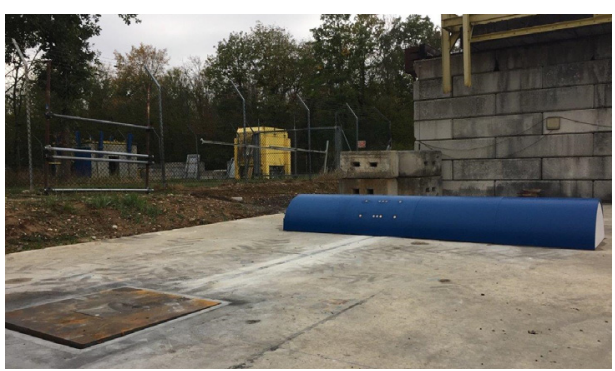

(a)

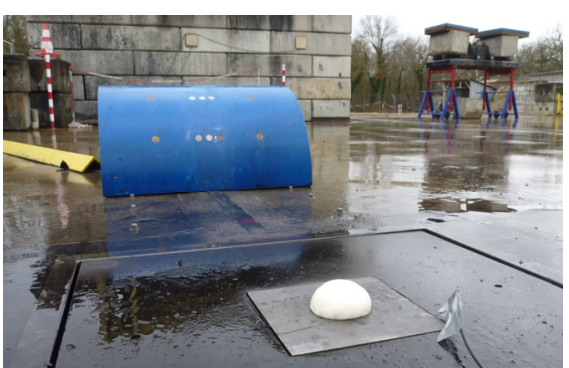

(b)

Figure 5: ISL setup with the "long" (a) and "short" (b) hemi-cylindrical obstacles.

Presented results were recorded at a distance d of $3.2 \mathrm{~m}$ at ISL scale (Table 1). Different types of pressure transducers were mounted on polypropylene supports inserted in the hemicylinder ports each separated by $30^{\circ}$. All data were recorded using a Transcom system running at $2 \mathrm{MHz}$.

\subsection{Pressure sensors positions}

The authors would like to draw the reader's attention to the fact that all distances presented in the rest of this document correspond to IRSN scale. ISL distances and times have all been downscaled for direct comparison. 
Table 1 presents the position of all sensors for hemi-cylinder tests at both scales (reduced distances $Z$ ranging between 0.57 and $4.6 \mathrm{~m} . \mathrm{kg}^{1 / 3}$ for a TNT equivalent spherical charge). IRSN hemi-cylinder centre line was equipped with five Kistler $603 \mathrm{~B}$ sensors every $30^{\circ}$. For the ISL obstacle, five PCB 113B28 sensors populated the centre line whereas a $50 \mathrm{~mm}$ distant (ISL scale) line included five Kulite XT190 sensors (Table 1).

\subsection{Explosive charges}

The explosive charges consisted of Hexomax ${ }^{\circledR}$ hemispheres, initiated from the bottom using an electrical detonator (Davey-Bickford SA-4201 at IRSN or RP83 at ISL). For these tests, the used masses were $41.6 \mathrm{~g}$ (IRSN) and $333 \mathrm{~g}$ (ISL) of Hexomax ${ }^{\circledR}$ (50 and $400 \mathrm{~g}$ respectively in TNT overpressure equivalent). Each charge was placed directly either on the table (IRSN) or the blast surface (ISL) as seen in Fig. 6. Charges characteristics are reported in Table 2.

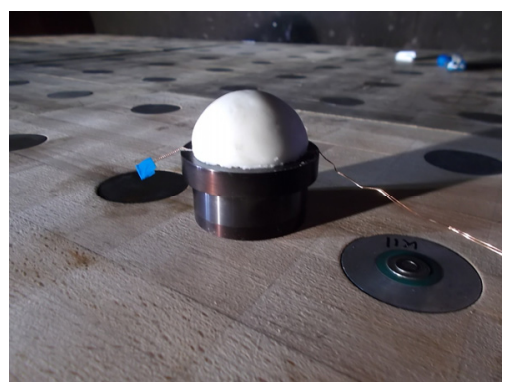

(a)

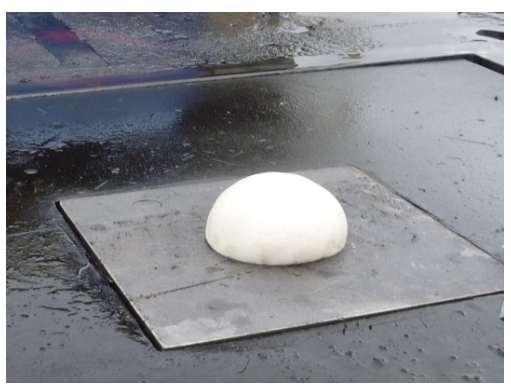

(b)

Figure 6: Hexomax ${ }^{\circledR}$ charges. (a) IRSN; and (b) ISL.

Table 2: Explosive charges characteristics.

\begin{tabular}{|l|c|c|}
\hline Configuration & IRSN & ISL \\
\hline Mass $(\mathrm{g})$ & 41.6 & 333 \\
\hline Diameter (mm) & 46.6 & 94 \\
\hline Density $\left(\mathrm{g} / \mathrm{cm}^{3}\right)$ & 1.58 & 1.54 \\
\hline Igniter & SA-4201 & RP83 \\
\hline Pressure TNT eq. (g) & 50 & 400 \\
\hline
\end{tabular}

\section{EXPERIMENTAL RESULTS AND ANALYSIS}

\subsection{Overpressure evolution at the hemi-cylinder surface}

Overpressure evolutions along the IRSN hemi-cylinder central line versus angle of observation are presented in Fig. 7 for the three different d distances: 0.4, 0.6 and 1.6 m. Each represented point corresponds to the average of three experimental measurements. Peak overpressure values decrease with the angular position on the obstacle as the compression decreases before the transition to the expansion on the backside. A similar trend seems to appear for all distances $\mathrm{d}$ after $90^{\circ}$. Mach transitions angles are estimated at $28^{\circ}, 30^{\circ}$ and $44^{\circ}$ respectively for $0.4,0.6$ and $1.6 \mathrm{~m}$ according to Kinney and Graham [8]. 


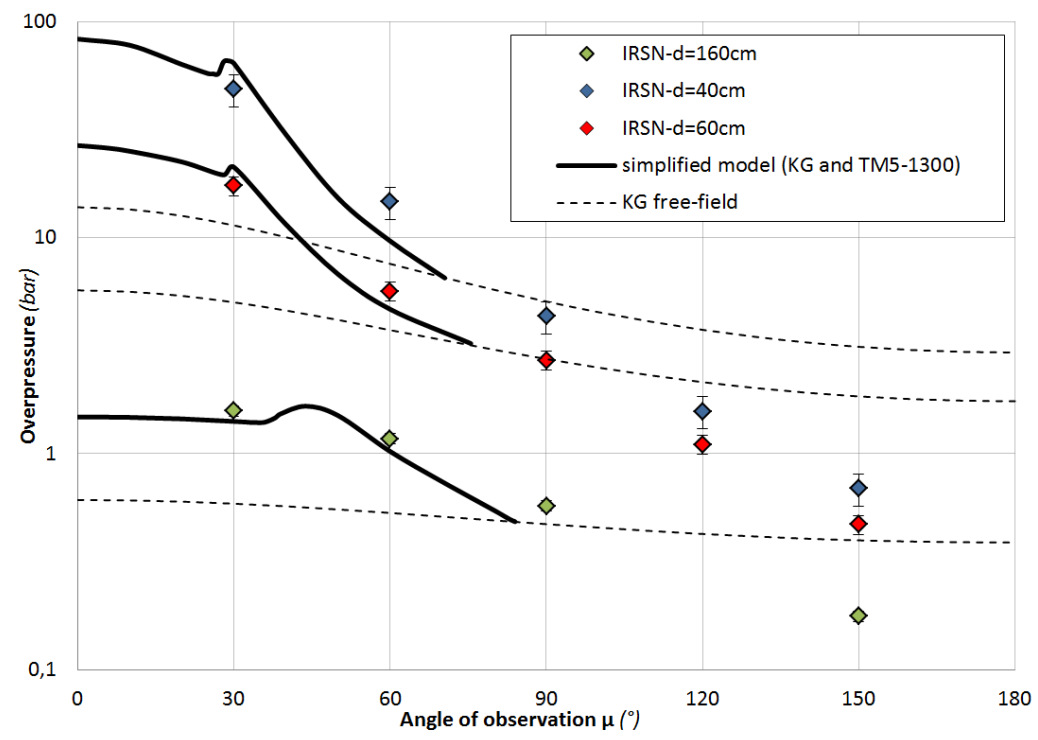

Figure 7: Overpressure evolution on the central line for the $0.4,0.6$ and $1.6 \mathrm{~m}$ distances at IRSN scale [5], [6], [8], [9].

Free-field overpressures for an incident wave according to the Kinney and Graham theory [8] are also represented on the same graph in dashed line. Another simplified model [8]-[10] represented in black lines is based on TM5-1300 [9]: reflection coefficients are determined for planar targets and corresponding incident angle and overpressure. These data are only plotted for the reflection face of the target, as the model is not able to predict the wave diffraction on the opposite side.

On the blast-exposed face, average measurements are in reasonable agreement with the model (up to $50 \%$ discrepancy). The limited number of angular positions for the sensor however prevented us from determining the position of the classic "knee" on the pressure evolution.

At $60^{\circ}$, after the formation of the Mach stem, the peak reflected overpressures are greater than those predicted by the simplified model: this can be explained by the Mach stem curvature above the convex shape (Fig. 12).

At $90^{\circ}$, at the beginning of the expansion zone, the measured overpressures are slightly higher than the free-field values.

At $150^{\circ}$, overpressures behind the obstacle are at least $55 \%$ lower than for free-field at the same position, demonstrating the blast mitigating effect of the hemi-cylinder.

\subsection{Transmission coefficient}

Transmission coefficient versus direct distance to the measurement point is presented in Fig. 8 for IRSN measurements. This coefficient is defined by the ratio between the measured and the predicted free-field [8] overpressures at the considered position (direct distance from the charge centre to the considered position at the hemi-cylinder surface). This consequently corresponds to a classic reflection coefficient on the obstacle front surface. On the expansion side of the obstacle, it illustrates the obstacle's ability to reduce the overpressure by 
diffracting the incoming blast wave. The angle of vision limit is materialized for each configuration by a dashed vertical line in Fig. 8. This definition of the transmission coefficient differs from the classic shock interaction with a hemi-cylindrical shape approach considering a constant reference pressure: previous studies usually focus on $2 \mathrm{D}$ cylinders submitted to a steady pressure wave generated by a far-field large-scale blast [11] or inside a shock tube [12], [13]. For this study, the 3D blast wave intensity decreases as it propagates and interacts with the finite hemi-cylinder.

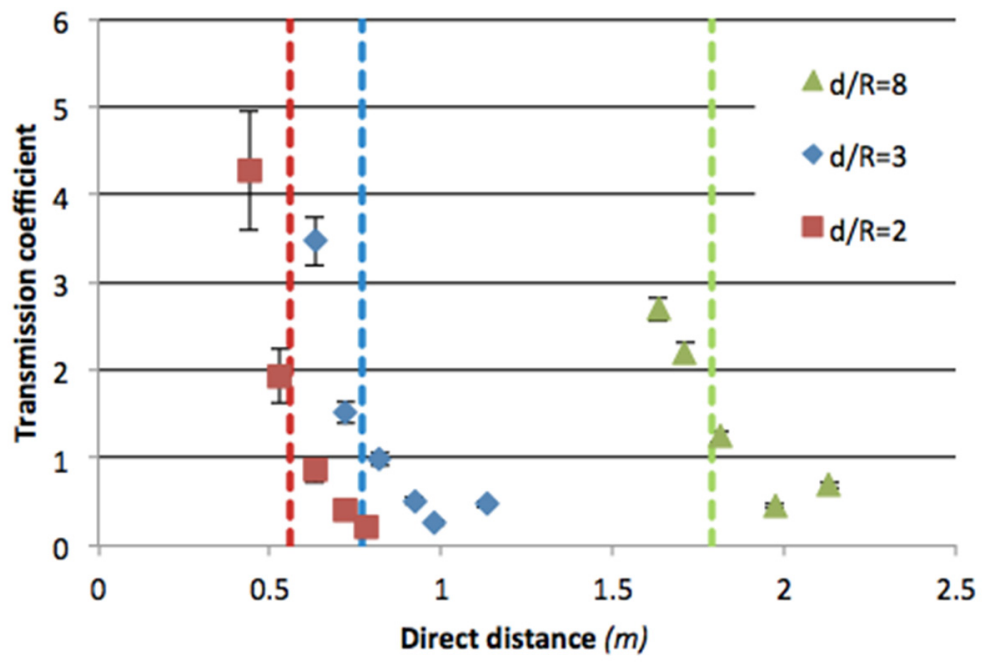

Figure 8: Transmission coefficient evolution along the central line versus direct distance [5], [6].

Transmission coefficient values are comprised between 1.25 and 4.5 before the angle of observation limit, in agreement with literature [9]. After the limit angle, it decreases from 1 down to 0.2 .

This approach is based on the direct distance evolution. The deployed distance evolution could be considered as well.

Based on these results, an innovative approach of the transmission coefficient evolution is proposed by analyzing its variation depending on the direct distance with an origin shifted to the beginning of the expansion zone (Fig. 9) and divided by the hemi-cylinder radius to obtain a reduced shifted direct distance (RSDD): in this region of the hemi-cylinder surface (RSDD comprised between 0 and 1.2), corresponding to different angular ranges for each configuration, all values seem to follow a similar trend for the three different values of $d / R$ (2, 3 and 8$)$.

From the observations in Fig. 9, an experimental correlation, eqn (1), was proposed (named Model S) and illustrated in Fig. 10:

$$
\mathrm{Ct}=0.396 \times \mathrm{RSDD}^{2}-1.4385 \times \mathrm{RSDD}+1.347,
$$

where

- $\quad \mathrm{Ct}$ : transmission coefficient (dimensionless);

- RSDD: reduced shifted direct distance (dimensionless). 


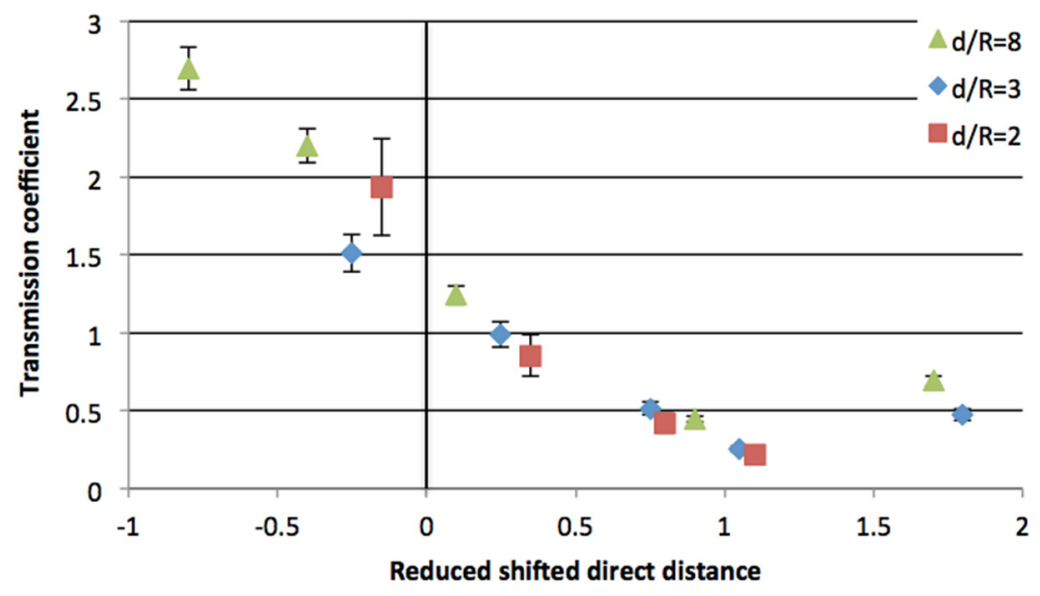

Figure 9: Transmission coefficient evolution along the central line versus reduced shifted direct distance (RSDD).

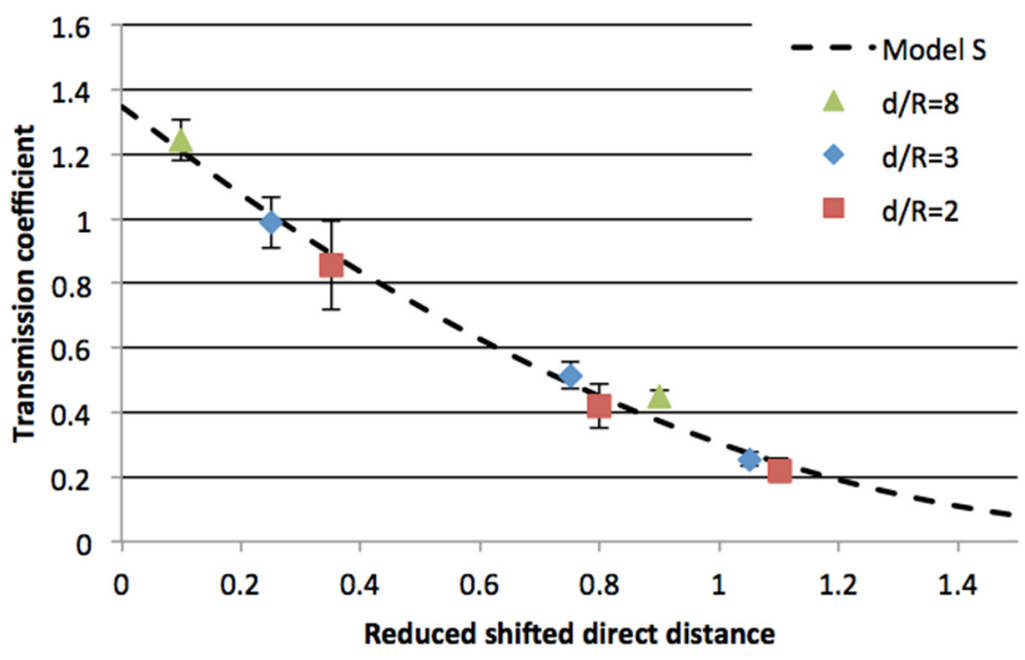

Figure 10: Transmission coefficient evolution - experiments versus Model S.

Finally, Fig. 11 presents IRSN overpressure data collected versus angle of observation in comparison with literature (KG free-field [8] and TM5-1300 [9]) and Model S correlations determined with IRSN results (for the $3 \mathrm{~d}$ distances $0.4,0.8$ and $1.6 \mathrm{~m}$ ). Model $\mathrm{S}$ is plotted by solid coloured lines on the angular range of validity (from the critical angle of observation to $180^{\circ}$ ) and extended on the shock reflection front face in dashed coloured lines.

All ISL scale peak overpressures recorded for short and long hemi-cylinders $(\mathrm{d}=3.2 \mathrm{~m})$ using PCB and Kulite sensors are added as green symbols in Fig. 11. The Model S correlation provides a convincing prediction of the $400 \mathrm{~g}$ TNT equivalent experimental overpressure 


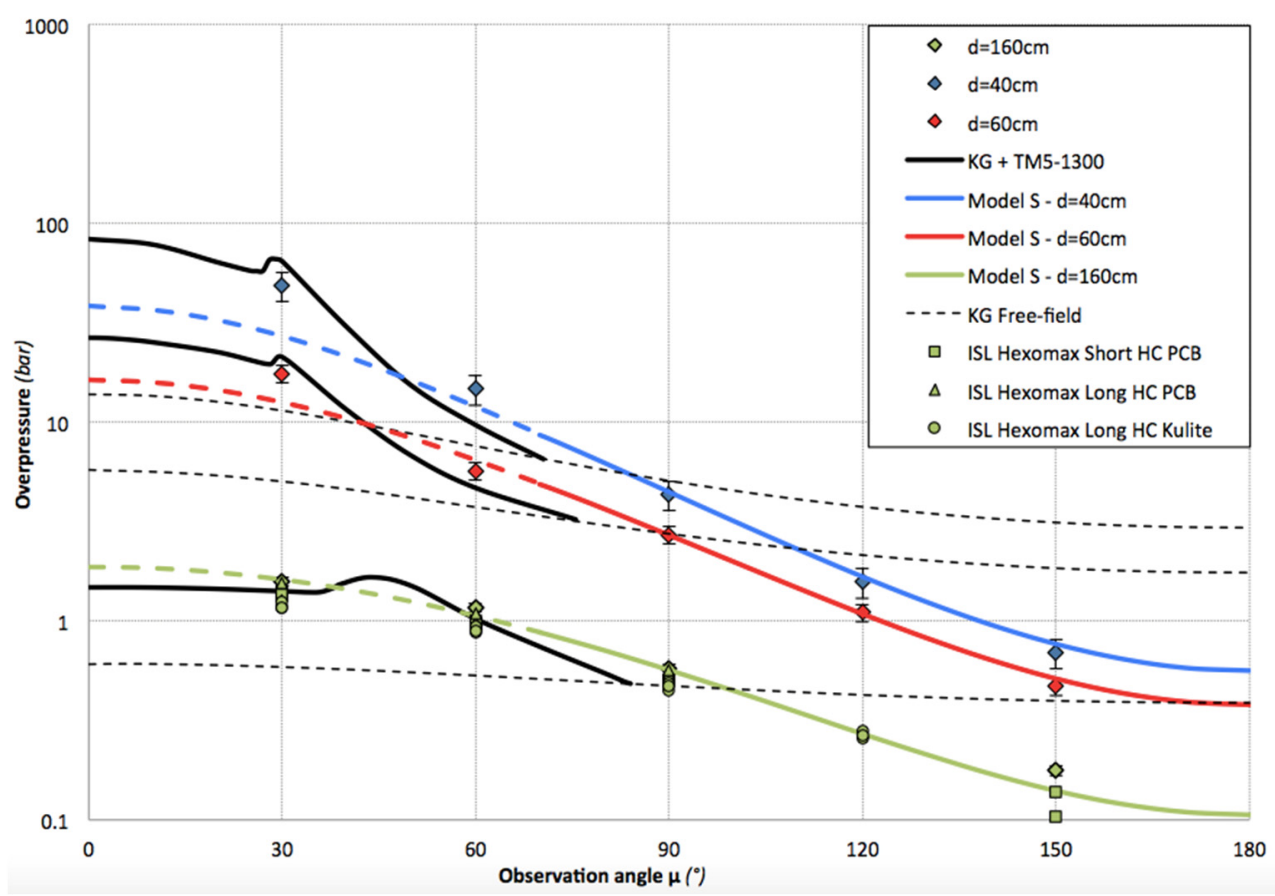

Figure 11: Overpressure evolution versus angle of observation on the hemi-cylinder central line - experimental data versus Model S.

evolution on the back side of the upscaled obstacle. Results dispersion at $150^{\circ}$ can be explained by the expansion phenomenon itself, the proximity of a welding joint next to the sensor positions as well as the difference in the responses of the pressure gauges [14]. This first inter-scale comparison strengthens the pertinence of the Model S conjecture to predict peak overpressure evolution on the expansion side of a cylindrical target exposed to a blast wave for any $\mathrm{d} / \mathrm{R}$ ratio and charge mass by defining a reduced shifted direct distance. This model completes the TM5-1300 approach for the complex unsteady gas-dynamic interaction phenomena [11].

\section{HIGH SPEED IMAGING}

Fig. 12 illustrates the evolution of the blast wave interaction with the ISL hemi-cylinder on high-speed images $5.94 \mathrm{~ms}$ after a $333 \mathrm{~g}$ Hexomax $^{\circledR}$ charge detonation at $3.2 \mathrm{~m}$ (ISL scale) from the obstacle. Background Oriented Schlieren (BOS) [15] was chosen to enhance the visibility of the shock propagation [6]. BOS image is presented below the original record. At this stage of the propagation, the three characteristic waves (incident, reflected and Mach) are visible, merging on the triple point.

Fig. 13 shows the triple point radius (left) and velocity (right) versus time evolutions [6]. These data were extracted from the high-speed images recorded for the same Hexomax ${ }^{\circledR}$ test.

The triple point appears $5 \mathrm{~ms}$ after the explosive charge detonation and propagates at an average of $450 \mathrm{~m} / \mathrm{s}$ between 5 and $7 \mathrm{~ms}$. This technique based on BOS consequently permits an accurate tracking of the triple point and the global structure of the reflected wave on the convex shape. 


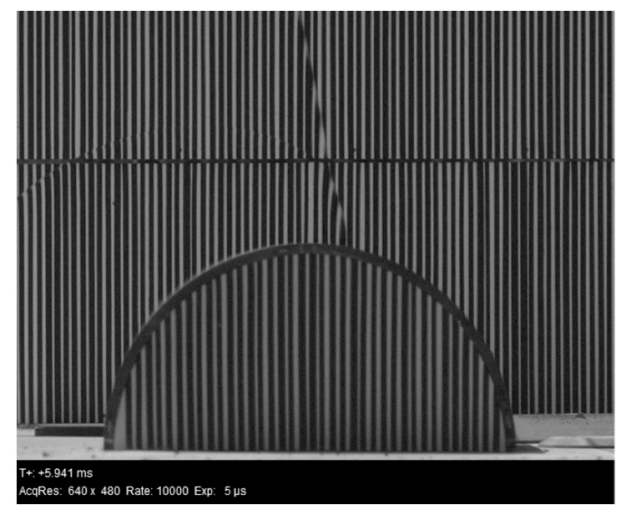

(a)

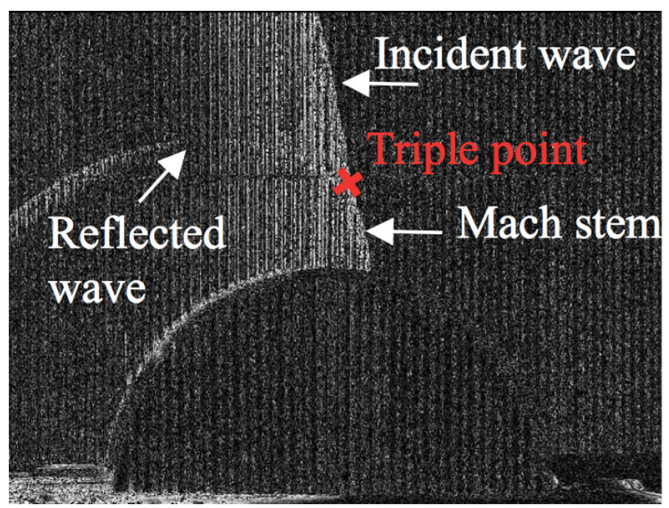

(b)

Figure 12: Blast wave interaction with the hemi-cylindrical target.

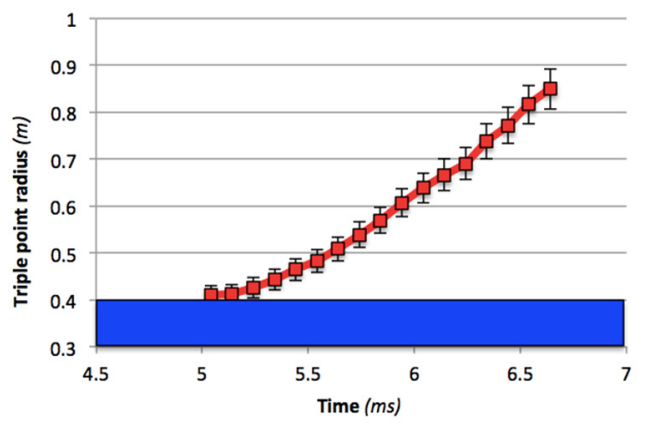

(a)

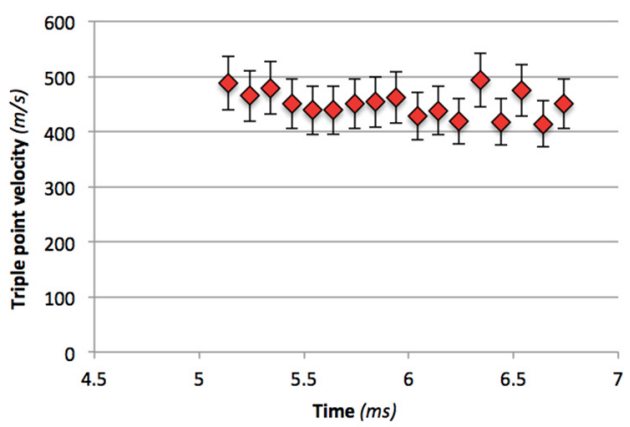

(b)

Figure 13: Triple point radius (a) and velocity (b) versus time evolution.

\section{CONCLUSION AND PERSPECTIVES}

Blast wave interaction with a convex structure was investigated by IRSN and ISL through a twin reduced scale experimental approach. The effects of hemispherical Hexomax ${ }^{\circledR}$ charges were characterized at the surface of a hemi-cylindrical obstacle. Based on the $42 \mathrm{~g}$ charge (50 g TNT equivalent) configuration defined in previous IRSN work, ISL designed a factor 2 up-scaled setup by using $333 \mathrm{~g}$ Hexomax ${ }^{\circledR}$ hemispheres (400 g TNT equivalent). Blast wave propagation was analysed through the peak overpressure recorded with different types (piezo-electric and piezo-resistive) of pressure sensors placed at the target surface.

Overpressure evolutions along the IRSN hemi-cylinder central line were determined for three distances to the explosive charge. Results are compared to a reflected face simplified model (TM5-1300 [9] + Kinney and Graham [8]) and free-field side on overpressure (Kinney and Graham [8]). A good agreement is observed between experimental data and the simplified model on the directly exposed face of the obstacle. To predict the blast load on the expansion side in a similar way, transmission coefficients are represented as functions of an innovative parameter: the reduced shifted direct distance (RSDD). By taking into account the geometry of the obstacle and the 3D free-field pressure decay, this physical conjecture (Model S) allows the prediction of the peak overpressure evolution on the expansion side of 
the ISL hemi-cylinder at double scale. An experimental campaign conducted in January 2020 confirmed the extension of this conjecture to other charge masses and $d / R$ ratios [16]. This model will also be extended to other blast parameters such as positive phase impulse and duration. This type of tool will prove to be useful to perform structural finite element analysis or to take part in the design of real critical infrastructure by government agencies in addition to other classic tools [17] able to predict average loading on blast exposed surfaces.

\section{REFERENCES}

[1] Cheval, K., Loiseau, O. \& Vala, V., Laboratory scale tests for the assessment of solid explosive blast effects. Part I: Free-field test campaign. Journal of Loss Prevention in the Process Industries, 23(5), pp. 613-621, 2010.

[2] Cheval, K., Loiseau O. \& Vala V., Laboratory scale tests for the assessment of solid explosive blast effects, Part II: Reflected blast series of tests. Journal of Loss Prevention in the Process Industries, 25(3), pp. 436-442, 2012.

[3] Trélat, S., Impact de fortes explosions sur les bâtiments représentatifs d'une installation industrielle. PhD thesis, Université d'Orléans, France, 2006.

[4] Sochet, I., Blast Effects, Springer Verlag, 2018.

[5] Van Dorsselaer, N., Eveillard, S. \& Trélat, S., Experiments and simulations of explosives: Shock wave propagation around a convex structure. Proceedings of the 15th International LS-DYNA ${ }^{\circledR}$ Users Conference, 2018.

[6] Trélat, S., Sturtzer, M.-O., Eveillard, S., Eckenfels, D., Mory, J., Legendre, J.-F., Braina, F. \& Soubiès, B., Strong explosion near a convex structure: A multi-scale experimental study. Proceedings of the 25th International Symposium on Military Aspects of Blast and Shock, 2018.

[7] Trélat, S. \& Sturtzer, M.-O., Predicting explosion and blast effects: A multi-scale experimental approach. International Journal of Safety and Security Engineering, 9(4), pp. 356-370, 2019.

[8] Kinney, G.F. \& Graham, K.J., Explosive Shocks in Air, Springer Verlag, 1985.

[9] TM5-1300, Technical Manual, Structures to Resist to the Effects of Accidental Explosions, 1990.

[10] Duong, D.H., Hanus, J.L., Bouazaoui, L., Pennetier, O., Moriceau, J., Prod'homme, G. \& Reimeringer, M., Response of a tank under blast loading, Part I: Experimental characterization of blast loading arising from a gas explosion. European Journal of Environmental and Civil Engineering, 16(9), pp. 1023-1041, 2012.

[11] Glasstone, S \& Dolan, P.J., The Effects of Nuclear Weapons, 3rd ed., US Government Printing Office, 1962.

[12] Drikakis, D., Ofengeim, D., Timofeev, E. \& Voionovich, P., Computation of nonstationary shockwave/cylinder interaction using adaptive-grid methods. Journal of Fluids and Structures, 11(6), pp. 665-692, 1997.

[13] Takayama, K. \& Kawauchi, T., The transition from regular to Mach reflection in truly non-stationary flows. Journal of Fluid Mechanics, 100, pp. 147-160, 1979.

[14] Sturtzer, M.-O., Trélat, S. \& Sinniger, L., Investigation on the post-processing of blast loading characteristics along a convex structure. 16th International Conference on Structures under Shock and Impact, 22-24 June, Lisbon, Portugal, 2020.

[15] Grégoire, Y., Etude expérimentale et numérique de la dispersion explosive et de la combustion de particules métalliques. $\mathrm{PhD}$ thesis, Ecole Nationale Supérieure de Mécanique et d'Aérotechnique, France, 2009. 
64 Structures Under Shock and Impact XVI

[16] Trélat, S., Sturtzer, M.-O., Eckenfels, D., Mano, C., Braina, F. \& Legendre, J.-F., High explosives blast propagation along a hemi-cylindrical obstacle: influence of pressure gauge technology on the overpressure characteristics. 26th International Symposium on Military Aspects of Blast and Shock, 15-20 November, Wollongong, Australia, 2020.

[17] UFC 3-340-02, Structures to Resist the Effects of Accidental Explosions, Department of Defense, USA, 2008. 